\title{
A Toast to the Last Decade and a Very Happy 2020 from Thrombosis and Haemostasis!
}

\author{
Gregory Y. H. Lip ${ }^{1,2}$ Anne Rigby ${ }^{3}$ Christian Weber ${ }^{3,4,5}$
}

${ }^{1}$ Liverpool Centre for Cardiovascular Science, University of Liverpool, Liverpool, United Kingdom

2 Aalborg Thrombosis Research Unit, Department of Clinical Medicine, Aalborg University, Aalborg, Denmark

${ }^{3}$ Institute for Cardiovascular Prevention (IPEK), LMU Munich, Munich, Germany

${ }^{4}$ German Centre for Cardiovascular Research (DZHK), partner site Munich Heart Alliance, Germany

${ }^{5}$ Department of Biochemistry, Cardiovascular Research Institute Maastricht (CARIM), Maastricht University Medical Centre, the Netherlands

Thromb Haemost 2020;120:1-4.

We are very happy to start 2020 with our traditional January Editorial and Editor's Choice, ${ }^{1-4}$ especially as this year commemorates a special date for us. Ten years ago, Thrombosis and Haemostasis endowed itself for the first time with two Editorsin-Chief, one each for Basic and Clinical Science. We are very grateful for this fruitful collaboration and these past 10 years working with you, our authors, readers and reviewers.

In 2019, we could once more count on around 900 submissions from you, a number that has remained stable and portrays the confidence you have in Thrombosis and Haemostasis. Our Impact factor and CiteScore have maintained a stable trend in comparison to others in the field, specifically reflected by the CiteScore Percentile in the category hematology, which matched near 90th, over

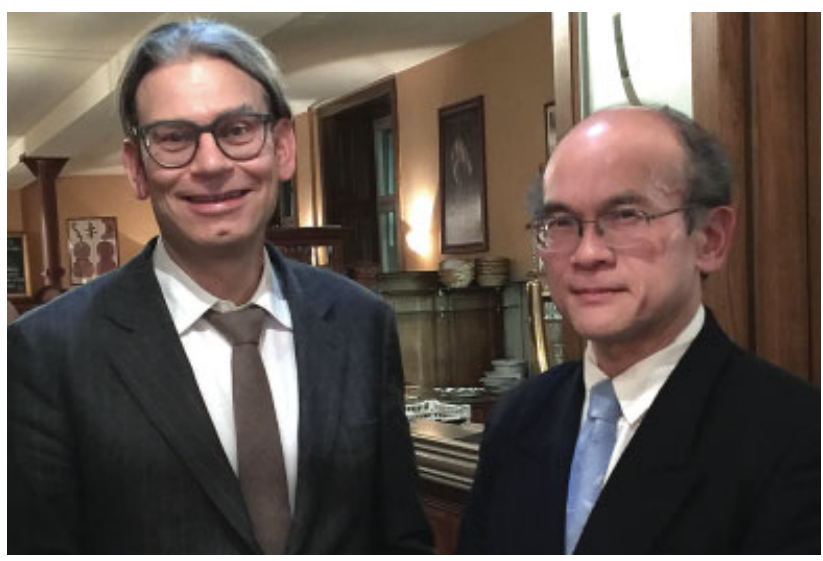

Christian Weber and Gregory Y. H. Lip at a conference in Basel, 2017.

received

November 23, 2019

accepted

November 23, 2019

Address for correspondence Gregory Y. H. Lip, MD, Liverpool Centre for Cardiovascular Science, University of Liverpool, William Henry Duncan Building, 6 West Derby Street, Liverpool L7 8TX, United Kingdom (e-mail: gregory.lip@liverpool.ac.uk). Christian Weber, MD, Institute for Cardiovascular Prevention, LMU Munich, Pettenkoferstraße 9, 80336 Munich, Germany (e-mail: chweber@med.Imu.de).

the past 5 years. We continue to serve as a link journal for the European Society of Cardiology Working Groups on Thrombosis and on Atherosclerosis and Vascular Biology, as well as being the official journal of the Society of Thrombosis and Hemostasis Research (GTH), the Spanish (SETH) society on Thrombosis and Haemostasis and the Australian Vascular Biology Society (AVBS).

\section{Reviewers}

We are indebted to our near 900 dedicated referees who do their best in providing reviews in a timely, highly competent and comprehensive manner.

We have to particularly praise our top 10 reviewers for 2019:

- Diana Gorog

- Stefano Barco

- Erik Klok

- Robert Storey

- Bernd Jilma

- Marco Proietti

- Sergio Buccheri

- Moniek de Maat

- Anne-Mette Hvas

- David Jiménez

\section{Section Editors}

We have been very lucky to rely on the expertise and dedication from 66 section editors last year. We bid farewell to Georg Breier (Germany), Elaine Hylek (United States), Lee Lai-Heng

(c) 2020 Georg Thieme Verlag KG Stuttgart · New York
DOI https://doi.org/ $10.1055 / \mathrm{s}-0039-3402054$. ISSN 0340-6245. 
(Singapore) and John McVey (United Kingdom). We want to express our deepest gratitude to them for these many years of partnership when we have been able to count on their professionalism, valuable insights and opinions. We are looking forward to future collaboration and communication.

We also give a warm welcome to our new colleagues on the Editorial Board: Dániel Aradi (Hungary), Noel Chan (Canada), Tze-Fan Chao (Taiwan), Tobias Geisler (Germany), Yutao Guo (China), Kerstin Jurk (Mainz), Joao Morais (Portugal), Andrew Murphy (Australia), Ingrid Pabinger (Austria) and Peter Verhamme (Belgium), who have joined us as new section editors.

A special thank you goes to our last year's 10 most proactive section editors:

- Job Harenberg

- Samuel Goldhaber

- Dominick Angiolillo

- Rory Koenen

- Deirdre Lane

- John Eikelboom

- Davide Capodanno

- Vera Ignjatovic

- Geoff Barnes

- Tatjana Potpara

\section{What's New?}

\section{Theme Issues, Special Focuses and Historical Perspectives}

We are pleased to have published a series of theme issue articles last year, some of which already received notable attention. One theme issue focused on new therapeutic targets for atherosclerosis, ${ }^{5-17}$ the other one on platelets and the balance between aggregation and bleeding. ${ }^{18-23} \mathrm{We}$ are looking forward to publishing a new theme issue this year on Reversal of Oral Anticoagulant Therapy. Moreover, we have published a very necessary special focus article on the Clinical Use of Biomarkers last year ${ }^{24}$ and plan one on the hot topic of NETs and Thrombosis this year.

Inevitably, today's issues in thrombosis or haemostasis take their roots in the findings and failures from the past. We decided to celebrate the full retro-digitalization of Thrombosis and Haemostasis since the first published issue in 1957 (then under the name Thrombosis et Diasthesis Haemorrhagica), by inviting "historical perspective articles". The first of this kind focused on the management of stroke through the decades ${ }^{25}$ and we are looking forward to publishing another on platelet inhibition this year.

\section{TH Open}

We are pleased to announce that TH Open, our open access companion journal launched in 2017, is now listed on PubMed Central and the Directory of Open Access Journals. Its unique "pay-what-you-want" policy gives everyone a chance to submit open access. As an open access publication, all articles in $\mathrm{TH}$ Open are freely available at www.thieme.com/tho.

\section{Visual Summaries}

We are excited to implement engaging "visual summaries" to accompany every original article and review this year. This should convey the main message of the manuscript in a clear and concise manner so that readers can grasp its contents and relevance at a glance. With the manuscript's title, it is what will capture the reader's interest to read the whole paper. The figure below illustrates how visual summaries can look like, here in the context of the journal's impact and

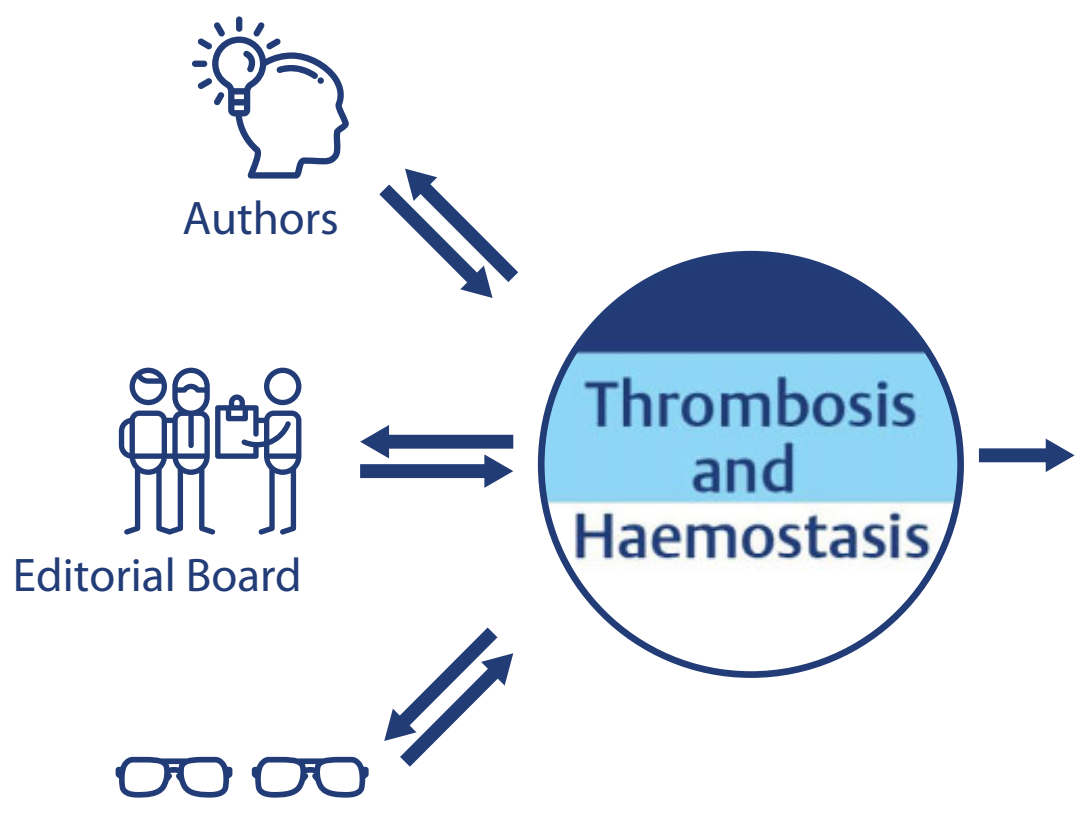

\section{Reviewers}

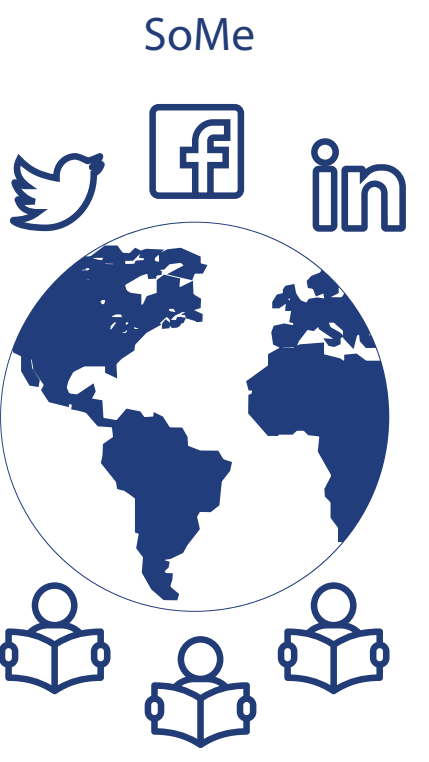

Readers

Visual summary: factors driving Thrombosis and Haemostasis quality and visibility. Figure realized with icons freely available at www.flaticon. com. For guidelines and suggestions to elaborate visual summaries, please refer to our author's guidelines. 
reach. In an era where research findings are ever more disseminated through social media, such visual aids become essential.

\section{Stay Tuned and Be Social!}

We are delighted to have appointed Tatjana Potpara and Marco Proietti as social media editors last year. They have been actively promoting specific manuscripts and news on our social media platforms including Twitter, Facebook and LinkedIn. We have also published more than 20 short written interviews from first authors last year. We were pleased that the interview from Michael Fiechter on his manuscript on sex differences in inflammation and ischemic heart disease ${ }^{26}$ was read over 600 times and that from John Fanikos on the clinical management of reversal agent idarucizumab ${ }^{27}$ was relayed 80 times. We plan more interactivity on Twitter this year, including live discussions on specific issues and theme issue polls.

We encourage you to pay us a visit on our social media pages and to share your work via your social media networks (have a look at our social media guide https://www.thieme.com/images/stories/PDF/Social_Media_Brochure.pdf) for best impact and reach.

\section{Challenging the Dogma}

We would like to make a final remark on the past decades' growing disequilibrium between unbiased and hypothesisdriven research with the advent of the -omics era. One might argue that there is actually a bias against hypothesis-driven and heuristic research in many major journals. In large conferences, presenters ironically acknowledge the fact if their talk does not contain references or results derived from big data such as GWAS, RNAseq or t-SNE (T-distributed Stochastic Neighbor Embedding).

At Thrombosis and Haemostasis, we strongly believe that both forms and modalities of research need to complement and inform each other to produce the most relevant research output. That said it does not necessarily have to occur in one manuscript. Hence, we strongly encourage and support our authors in continuing to create and probe new and provocative hypothesis that may even be counterintuitive or challenge existing dogma, provided that the experimental path is rigorously controlled.

Indeed, this can serve as an excellent path to break prevailing dogma and is a prerequisite for the ( $r$ )evolution of our research communities. As Albert Einstein put it: "Blind belief in authority is the greatest enemy of truth." Thus, we further strongly encourage our authors to think and hypothesise against the trend, as long as the evidence collected sufficiently supports the conclusions and there is no other evidence falsifying it.

In conclusion, along with the entire editorial staff including Elinor Switzer (Stuttgart), and Thieme Publisher (Stuttgart), we would again like to sincerely thank our authors for their interest, trust and engaging work as well as our section editors and reviewers, for their dedication and thoroughness.
As editors, we have greatly enjoyed our past 10 years. We will keep bringing new ideas and innovations to your journal and are looking forward to an exciting New Year 2020 at Thrombosis and Haemostasis, may the journal keep being such an important source to clinicians and scientists!

We wish you very exciting 2020 , filled with much scientific curiosity and great success!

\section{Conflict of Interest}

G.Y.H.L. reports consultancy and speaker fees from Bayer, Bayer/Janssen, BMS/Pfizer, Biotronik, Medtronic, Boehringer Ingelheim, Microlife, Roche and Daiichi-Sankyo outside the submitted Work. No fees received personally.

\section{Acknowledgment}

We thank Dr. Johan Duchêne for his help with elaborating the visual summary figure. Icons made by Freepik and Smashicons from www.flaticon.com

\section{References}

1 Lip GYH, Weber C. A happy new year from a 60-year-old journal 'Thrombosis and Haemostasis'!. Thromb Haemost 2018;118 (01):1-3

2 Lip GYH, Weber C. Thrombosis and haemostasis wishes you a happy new year ahead!. Thromb Haemost 2019;119(01):1-2

3 Weber C, Lip GYH. Editors' choice in the 60th anniversary year of thrombosis and haemostasis: past, present and future. Thromb Haemost 2018;118(01):225-227

4 Weber C, Lip GYH. Thrombosis and haemostasis 2018 editor's choice papers. Thromb Haemost 2019;119(01):183-186

5 Steffens S, Weber C. Immunotherapy for atherosclerosis-novel concepts. Thromb Haemost 2019;119(04):515-516

6 Kaltner H, Gabius H-J. Sensing glycans as biochemical messages by tissue lectins: the sugar code at work in vascular biology. Thromb Haemost 2019;119(04):517-533

7 Gencer S, van der Vorst EPC, Aslani M, Weber C, Döring Y, Duchene J. Atypical chemokine receptors in cardiovascular disease. Thromb Haemost 2019;119(04):534-541

8 Van Avondt K, Maegdefessel L, Soehnlein O. Therapeutic targeting of neutrophil extracellular traps in atherogenic inflammation. Thromb Haemost 2019;119(04):542-552

9 Sinitski D, Kontos C, Krammer C, Asare Y, Kapurniotu A, Bernhagen J. Macrophage migration inhibitory factor (MIF)-based therapeutic concepts in atherosclerosis and inflammation. Thromb Haemost 2019;119(04):553-566

10 Guillamat-Prats R, Rami M, Herzig S, Steffens S. Endocannabinoid signalling in atherosclerosis and related metabolic complications. Thromb Haemost 2019;119(04):567-575

11 Natarelli L, Weber C. Next-generation therapeutic concepts for atherosclerosis: focus on cell specificity and noncoding RNAs. Thromb Haemost 2019;119(08):1199-1201

12 Paloschi V, Winter H, Viola J, Soehnlein O, Maegdefessel L. Mechanistic links between non-coding RNAs and myeloid cell inflammation in atherosclerosis. Thromb Haemost 2019;119(08): 1205-1211

13 Busygina K, Denzinger V, Bernlochner I, Weber C, Lorenz R, Siess W. Btk inhibitors as first oral atherothrombosis-selective antiplatelet drugs? Thromb Haemost 2019;119(08):1212-1221

14 Holdt LM, Kohlmaier A, Teupser D. Long noncoding RNAs of the arterial wall as therapeutic agents and targets in atherosclerosis. Thromb Haemost 2019;119(08):1222-1236 
15 Joppich M, Weber C, Zimmer R. Using context-sensitive text mining to identify mirnas in different stages of atherosclerosis. Thromb Haemost 2019;119(08):1247-1264

16 Eckardt V, Weber C, von Hundelshausen P. Glycans and glycanbinding proteins in atherosclerosis. Thromb Haemost 2019;119 (08):1265-1273

17 Pircher J, Engelmann B, Massberg S, Schulz C. Platelet-neutrophil crosstalk in atherothrombosis. Thromb Haemost 2019;119(08): 1274-1282

18 Verheugt FWA. Platelets: the balance between aggregation and bleeding. Thromb Haemost 2019;19(10):1553

19 Kaikita K, Hosokawa K, Dahlen JR, Tsujita K. Total thrombusformation analysis system (T-TAS): clinical application of quantitative analysis of thrombus formation in cardiovascular disease. Thromb Haemost 2019;19(10):1554-1562

20 Stojkovic S, Nossent AY, Haller P, et al. MicroRNAs as regulators and biomarkers of platelet function and activity in coronary artery disease. Thromb Haemost 2019;19(10):1563-1572

21 Schrör K, Kristensen SD, Storey RF, Verheugt FWA. Aspirin and primary prevention in patients with diabetes-a critical evaluation of available randomized trials and meta-analyses. Thromb Haemost 2019;19(10):1573-1582
22 Sumaya W, Geisler T, Kristensen SD, Storey RF. Dual antiplatelet or dual antithrombotic therapy for secondary prevention in high-risk patients with stable coronary artery disease? Thromb Haemost 2019;19(10):1583-1589

23 Geisler T, Jorbenadze R, Popov A-F, et al. Thrombogenicity and antithrombotic strategies in structural heart interventions and nonaortic cardiac device therapy-current evidence and practice. Thromb Haemost 2019;19(10):1590-1605

24 Esteve-Pastor MA, Roldán V, Rivera-Caravaca JM, Ramírez-Macías I, Lip GYH, Marín F. The use of biomarkers in clinical management guidelines: a critical appraisal. Thromb Haemost 2019;119(12): 1901-1919

25 Ntaios G, Lip GYH. Stroke: insights into thromboembolism treatment and prevention through the decades. Thromb Haemost 2019;119(05):685-687

26 Fiechter M, Haider A, Bengs S, et al. Sex differences in the association between inflammation and ischemic heart disease. Thromb Haemost 2019;119(09):1471-1480

27 Fanikos J, Murwin D, Gruenenfelder F, et al. Global use of idarucizumab in clinical practice: outcomes of the REVECTO surveillance program. Thromb Haemost 2019;120 (02):27-35 